\title{
Healthier doctors, healthier patients
}

$\mathrm{S}$ ometimes healers need healing too. Physicians are prone to exhaustion and burnout, and they can fall prey to the same addictions and ailments as anybody else. Improving the health of doctors is critically important, suggest physician wellness experts. Not only for doctors and their families, but also for patients.

In fact, the state of a health care system can, in part, be attributed to the wellbeing of its doctors, suggests Dr. Jane Lemaire, clinical professor of medicine and vice chair of physician wellness and vitality in the Faculty of Medicine at the University of Calgary in Alberta.

"Burnout affects doctors. Would it not affect their work performance? If doctors are unwell, it has serious consequences for them, for their work and relationships. But it also has serious consequences for the health care system," says Lemaire, who has suggested with colleagues that physician wellness be routinely measured in health systems as a quality indicator (Lancet 2009;374:1714-21).

"When people are well, they thrive. Do we want our physicians to thrive? Or do we want them just hanging on by the skin of their teeth?"

Experts in the area hoped to address that issue when they gathered for the International Conference on Physician Health, a joint effort of the CMA, the British Medical Association and the American Medical Association, in Montréal, Que. Oct. 25-27.

In recent decades, the medical profession has done much to improve the health of doctors in Canada and abroad. There was a time, however, when the very notion of doctors talking about their own health and well-being was a foreign concept.

"When I went to medical school, there wasn't even a whiff of discussion about it," says CMA President Dr. Anna Reid, who has made improving the lives of burnt-out doctors a focal point of her presidency (www.cmaj.ca /lookup/doi/10.1503/cmaj.109-4262).

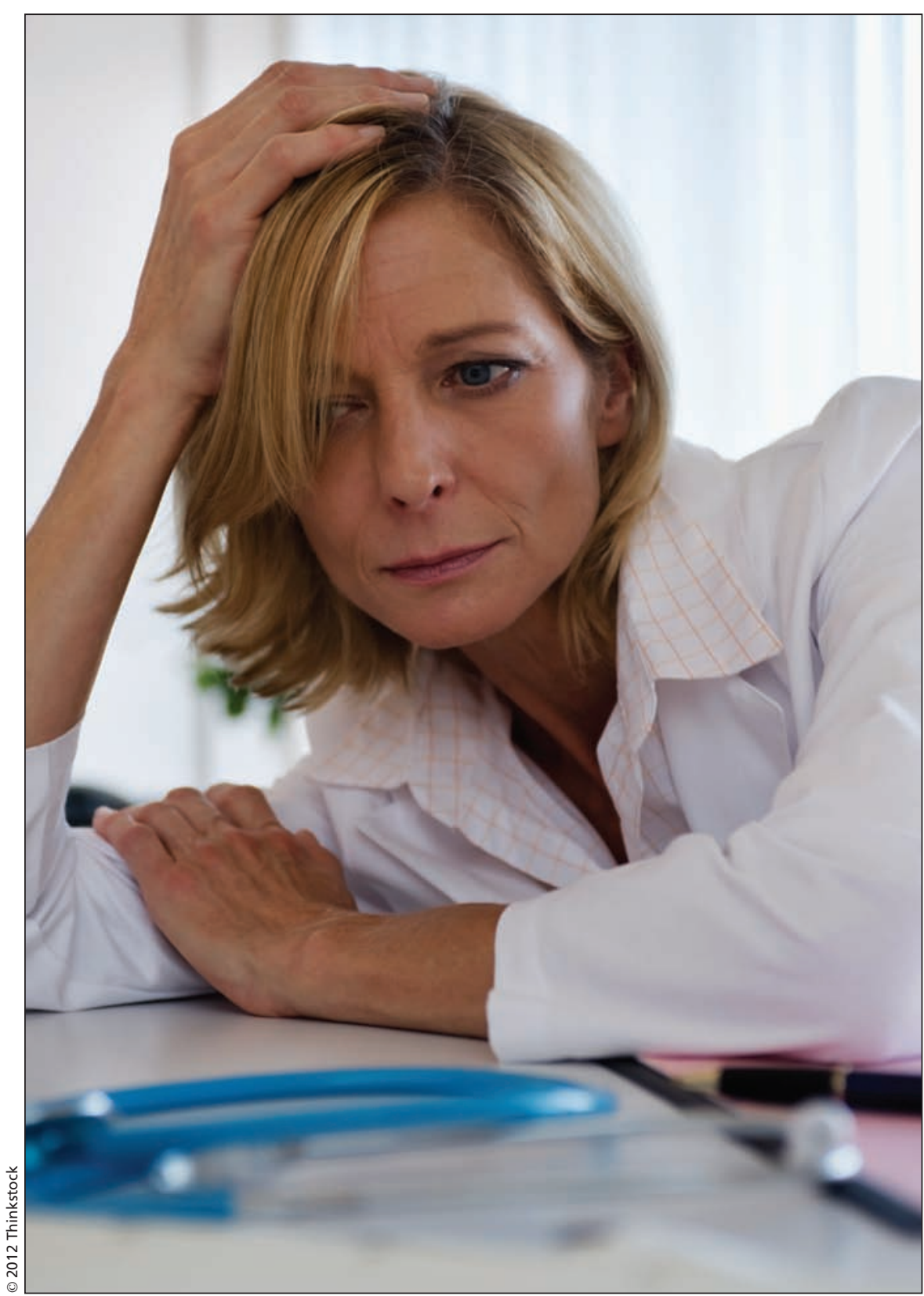

Burnout is common among doctors, thanks to factors such as long hours, dwindling resources, myriad demands and the stress of making life-and-death decisions.

Still, challenges abound. Stress will always be a factor in an emotional environment where death and disease are ever-present. Doctors still work long hours and belong to a culture that expects perfection. Resources shrink, responsibilities grow. Another obstacle is the reluctance of many physicians to acknowledge health problems for fear of stigma or professional repercussions. Even when they do admit to a problem, they can be reluctant to accept the role of patient.

"There is this attitude that we are the caregivers and not the care receivers," says Lemaire. 
To change attitudes and address needs, health systems in many countries have begun paying more attention to the health needs of doctors. There is a lot of work being done in this area in the United States, the United Kingdom and Australia. Canada is also considered a world leader in the field. It isn't top of mind, though, in developing nations struggling to provide basic health care. Even in some relatively well-off countries, the concept of physician well-being hasn't caught on.

"It's largely unheard of in Asia," says Dr. Derek Puddester, associate professor in the department of psychiatry at the University of Ottawa in Ontario, where he heads the medical school's Faculty Wellness Program. "And it's a bit of a dog's breakfast in Europe."

In Canada, programs vary in scope and form from province to province. "In the last few years, we have seen the growing influence of physician health programs in specific provinces," says Reid. "Ontario and Alberta have been leaders in this respect."

The College of Physicians and Surgeons of Ontario has a strong monitoring program to ensure physicians are complying with treatment for any condition that may affect their practices (www.cpso.on.ca/policies/guidelines /default.aspx?id=3316). The Alberta Medical Association's Physician and Family Support Program is frequently praised for its efforts to help not only medical professionals but also their immediate family members (www .albertadoctors.org/services/physicians /your-health/pfsp).

The province of Quebec excels in education and outreach in several areas of physician health, says Puddester, including fatigue management and work-life balance. Puddester is himself something of a pioneer in the field, having led the creation of ePhysicianHealth.com, the "world's first comprehensive, online physician health and wellness resource designed to help physicians and physicians in training be resilient in their professional and personal lives" (http ://ephysicianhealth.com).

Though there have been some national efforts to address the issue, including the new Canadian Physician Health Institute initiative being led by the CMA and the Canadian Medical Foundation, provinces are largely left to their own devices when creating a program. "There is no accreditation of physician health programs and no standardization," says Puddester.

A more formal approach to improving physician health might not be that far off. This could include not only guidelines but training programs and perhaps even certification in physician health. Experts warn, though, that taking a one-size-fits-all approach won't work. Physician health is complex. The needs of male doctors can differ from that of their female colleagues. The same goes for doctors from different generations.
The international conference is proof that interest in tackling the health problems that affect doctors is growing worldwide, despite the complexities, Puddester says. "It used to be small and attended by people in addiction recovery. Now it is a rich, scientific meeting. There is a notion that physician health is an emerging subspecialty of medicine, and the profession is moving, globally, toward this as a meaningful construct."

The concept of physician health has indeed evolved since the 1970s, when it was primarily understood as involving treatment for doctors with substance abuse problems. That later expanded to include mental health in general. Over the past decade, attention shifted to disruptive behaviour, which often stems from underlying mental health issues or addictions. More recently, promoting wellness to prevent health problems has been a priority. Wherever the focus shifts, says Puddester, it's important that doctors be taught to incorporate their health into their work if they wish to have sustainable careers.

"I think physicians are very bright people, and if we take a skill-based approach to these issues, they will learn it. If we take a motivational approach, involving shame, it won't work," says Puddester. "Doctors can make great patients once you teach them to be patients." - Roger Collier, CMAJ

CMAJ 2012. DOI:10.1503/cmaj.109-4327 